\title{
Knockdown of miR-128a induces Lin28a expression and reverts myeloid differentiation blockage in acute myeloid leukemia
}

Luciana De Luca*,1,9 Stefania Trino ${ }^{1,9}$, Ilaria Laurenzana ${ }^{1}$, Daniela Tagliaferri ${ }^{2}$, Geppino Falco ${ }^{2}$, Vitina Grieco ${ }^{3}$, Gabriella Bianchino ${ }^{3}$, Filomena Nozza ${ }^{3}$, Valentina Campia ${ }^{4}$, Francesca D'Alessio ${ }^{5}$, Francesco La Rocca ${ }^{1}$, Antonella Caivano ${ }^{1}$, Oreste Villani ${ }^{6}$, Daniela Cilloni ${ }^{4}$, Pellegrino Musto ${ }^{7,9}$ and Luigi Del Vecchio ${ }^{5,8,9}$

Lin28A is a highly conserved RNA-binding protein that concurs to control the balance between stemness and differentiation in several tissue lineages. Here, we report the role of miR-128a/Lin28A axis in blocking cell differentiation in acute myeloid leukemia (AML), a genetically heterogeneous disease characterized by abnormally controlled proliferation of myeloid progenitor cells accompanied by partial or total inability to undergo terminal differentiation. First, we found Lin28A underexpressed in blast cells from AML patients and AML cell lines as compared with CD34+ normal precursors. In vitro transfection of Lin28A in NPM1-mutated OCl-AML3 cell line significantly triggered cell-cycle arrest and myeloid differentiation, with increased expression of macrophage associate genes (EGR2, ZFP36 and ANXA1). Furthermore, miR-128a, a negative regulator of Lin28A, was found overexpressed in AML cells compared with normal precursors, especially in acute promyelocytic leukemia (APL) and in 'AML with maturation' (according to 2016 WHO classification of myeloid neoplasms and acute leukemia). Its forced overexpression by lentiviral infection in OCl-AML3 downregulated Lin28A with ensuing repression of macrophage-oriented differentiation. Finally, knockdown of miR-128a in OCl-AML3 and in APL/AML leukemic cells (by transfection and lentiviral infection, respectively) induced myeloid cell differentiation and increased expression of Lin28A, EGR2, ZFP36 and ANXA1, reverting myeloid differentiation blockage. In conclusion, our findings revealed a new mechanism for AML differentiation blockage, suggesting new strategies for AML therapy based upon miR-128a inhibition.

Cell Death and Disease (2017) 8, e2849; doi:10.1038/cddis.2017.253; published online 1 June 2017

Acute myeloid leukemia (AML) is a heterogeneous hematopoietic stem cell neoplasm, characterized by rapid growth and/or impaired differentiation of leukemic cells with abnormal accumulation. ${ }^{1-3}$ Recurring chromosomal aberrations and gene mutations contribute to AML pathogenesis and are the most important tools for classification and prognosis assessment of AML. ${ }^{2-4}$ Furthermore, there are some known deregulated pathways involved in the maintenance of leukemic stem cells such as hedgehog, ${ }^{5,6}$ tyrosine kinase receptors (e.g. Flt3), ${ }^{3,7}$ Wnt and Notch. ${ }^{8-11}$ Notwithstanding, a successful target therapy is not yet available. Improving our current knowledge on the biology of AML-associated leukemic processes represents a valuable tool to identify novel potential drug targets.

Lin28 is a conserved RNA-binding protein having an important role in cancer stem cells. ${ }^{12,13}$ This protein is expressed in embryonic stem cells ${ }^{14,15}$ and is capable, with OCT4, SOX2 and NANOG, of converting fibroblasts in induced pluripotent stem cells. ${ }^{16}$ Lin28, by physical interaction with several RNA transcripts, exerts various forms of regulation ranging from alternative splicing, turnover, localization and translation. ${ }^{17-19}$ It has been demonstrated that altered functionality of RNA-binding proteins, due to deregulated gene expression or gene mutations, often results in genetic disease and cancer. ${ }^{20}$

Several studies reported the existence of regulatory pathways between Lin28 and different miRNAs. ${ }^{15,21-23}$ In murine model, overexpression of miR-125b leads to the downregulation of Lin28A and the preleukemic state characterized by overproduction of myeloid cells eventually progressing to a myeloid leukemia. ${ }^{24-26}$ Conversely, ectopic expression of Lin28B reprograms hematopoietic progenitor cells from adult bone marrow (BM), endowing them to mediate multilineage reconstitution. ${ }^{27}$ Moreover, Li et al. ${ }^{22}$ showed that miR-181 promotes megakaryocytic differentiation repressing Lin28 and upregulating let-7 expression. Thus, Lin28 seems to be a pivotal regulator of hematopoiesis. Interestingly, Lin28 is also regulated by $m i R-128,{ }^{28}$ a microRNA able to hold hematopoietic cells in an early progenitor stage, blocking their

\footnotetext{
${ }^{1}$ Laboratory of Preclinical and Translational Research, IRCCS - Referral Cancer Center of Basilicata (CROB), Rionero in Vulture 85028, Italy; ${ }^{2}$ Biogem Scarl, Istituto di Ricerche Genetiche 'Gaetano Salvatore', Ariano Irpino 83031, Italy; ${ }^{3}$ Laboratory of Clinical Research and Advanced Diagnostics, IRCCS - Referral Cancer Center of Basilicata (CROB), Rionero in Vulture 85028, Italy; ${ }^{4}$ Department of Clinical and Biological Sciences, University of Turin, Orbassano 10043, Italy; ${ }^{5}$ CEINGE Biotecnologie Avanzate scarl, Naples 80147, Italy; ${ }^{6}$ Department of Onco-Hematology, IRCCS - Referral Cancer Center of Basilicata (CROB), Rionero in Vulture 85028, Italy; ${ }^{7}$ Scientific Direction, IRCCS - Referral Cancer Center of Basilicata (CROB), Rionero in Vulture 85028, Italy and ${ }^{8}$ Department of Molecular Medicine and Medical Biotechnologies, University of Naples Federico II, Napoli 80138, Italy

*Corresponding author: L De Luca, Laboratory of Preclinical and Translational Research, IRCCS - Centro di Riferimento Oncologico della Basilicata (CROB), via Padre Pio 1, Rionero in Vulture 85028, Italy. Tel: +39 0972 726528; Fax: +39 0972 723509; E-mail: dr.luciana.deluca@ gmail.com

${ }^{9}$ These authors contributed equally to this work.

Received 14.2.17; revised 05.5.17; accepted 05.5.17; Edited by M Diederich
} 
differentiation towards more mature cells. ${ }^{29,30}$ Moreover, this microRNA was found associated with AML. ${ }^{31-33}$ Therefore, it will be appealing to gain further insights into the role of miR-128a/Lin28A axis in induction and maintenance of an early differentiation status in AML.

\section{Results}

Lin28A expression was downregulated in myeloid leukemic cells. To evaluate Lin28A expression in AML, we performed quantitative real-time-PCR (qRT-PCR) in isolated blast cell samples from $38 \mathrm{AML}$ patients at diagnosis, $7 \mathrm{AML}$ cell lines (OCI-AML3, KG-1, Kasumi-1, NB4, CMK, ME-1 and MOLM-14) and CD34+ purified samples from 13 healthy donors. Lin28A $(P<0.01)$ and cell lines $(\mathrm{OCl}-\mathrm{AML} 3$ and $\mathrm{KG}-1$ $P<0.001$, Kasumi-1, NB4, CMK and ME-1, $P<0.01)$ showed a significantly lower expression in AML patients as compared with controls (Figure 1a). To support our data, we also analyzed two independent publicly available gene expression profiling data sets, one containing $16 \mathrm{CD} 34+$ isolated samples from healthy subjects (GSE 42519), and one with 251 AML patients with newly diagnosed AML (GSE 15434) confirming a significant downregulation of Lin28A in AML patients (230 BM and $21 \mathrm{~PB}$ ) compared with healthy subjects (Supplementary Figure 1a). Stratifying AML according to the WHO classification, ${ }^{4}$ Lin28A value was found underexpressed in all AML subtypes (Figure 1b) compared with controls. Stratifying AML cases according to the principal genomic alterations detected in our cohort of patients and in GSE 15434 data set, we found lower expression of Lin28A in AML patients independent of their specific alterations (Figure 1c and Supplementary Figure 1b). Moreover, we evaluated Lin28A protein by cytometric analysis detecting a lower percentage of Lin28A+ cells in AML blast cells compared with normal hematopoietic myeloid precursors $(P<0.01)$ (Figure 1d). When we analyzed distinct subsets of normal CD34+ cells, we observed a higher percentage of Lin28A+ cells in normal myeloid precursors (CD33+) compared with the erythroid $(C D 71+)(P<0.01)$ and lymphoid $(\mathrm{CD} 19+)(P<0.001)$ ones, suggesting its main involvement in myeloid differentiation (Figure 1e).

Lin28A overexpression induced hematopoietic differentiation in AML. To examine the effect of Lin28A in AML, we transfected OCl-AML3 cells with Lin28A plasmid. The significant increase of Lin28A protein expression was confirmed by western blot and cytofluorimetric analysis ( $P<0.01$ at $24 \mathrm{~h}$ and $P<0.05$ at $48 \mathrm{~h}$, in both cases) (Figures 2a-d). Lin28A overexpression was associated with the induction of monocyte/macrophage-like differentiation. In fact, flow cytometric analysis revealed a higher percentage of CD11b $-(P<0.05$ at $48 \mathrm{~h})$ and CD14+ cells $(P<0.01$ at $24 \mathrm{~h}$ and $P<0.001$ at $48 \mathrm{~h}$ ) after Lin28A transfection (Figures $2 \mathrm{e}-\mathrm{h})$. Ectopic expression of Lin28A also significantly increased p21 protein levels $(P<0.001$ at $24 \mathrm{~h}$ and $P<0.05$ at $48 \mathrm{~h})$, inducing cell-cycle arrest in the $S$ phase $(P<0.01$ at $24 \mathrm{~h}$ and $P<0.001$ at $48 \mathrm{~h}$ ) (Figures $2 \mathrm{a}$ and i). Consistent to the ability of Lin28A in inducing hematopoietic differentiation in AML cells, we detected a significant increase of EGR2 and
ZFP36, two key regulators of monocyte/macrophage differentiation (Figures $2 \mathrm{j}-\mathrm{k}$ ), ${ }^{34-36}$ and $A N X A 1$, a gene normally stored in inside macrophage cytosol (Figure 2l) ${ }^{37}$ after Lin28A overexpression at 24-48 h.

Lin28A expression increased during PMA or ATRA differentiation. To corroborate the involvement of Lin28A in myeloid differentiation, we stimulate $A M L$ cell lines to differentiate. In particular, we induced macrophage-like differentiation treating ME-1/OCI-AML3 cell lines with phorbol 12-myristate 13-acetate (PMA) and MOLM-14 with all-transretinoic acid (ATRA), and granulocyte-like differentiation treating NB4 and KG-1 cell lines with ATRA. After treatment, the cytometric data revealed a significant percent increase, from 24 to $72 \mathrm{~h}$, of CD11b+ cells and CD14+ cells in ME-1, OCl-AML3 (Figures $3 a$ and b) and NB4 (Supplementary Figure 2a), of CD11b and CD11c in MOLM-14 (Figure 3c) and of CD11b and CD15 in KG-1 (Supplementary Figure 2b). To confirm cytometric analysis of cell differentiation, we detected by qRT-PCR a significant augment, in all time points, of EGR2, ZFP36 and ANXA1 in treated ME-1, OClAML3, MOLM-14 (Figures 3d-f) and NB4 (Supplementary Figure 2c). ${ }^{37}$ As expected, at the same time, we observed a significant upregulation of Lin28A and an increased percentage of Lin28A+ cells in all cell lines (Figures $3 g-j$ and Supplementary Figures $2 \mathrm{~d}$ and e). Similarly to Lin28A transfection, PMA and ATRA treatment of AML cell lines also induced p21 expression (Figures $3 g-i)$ and a significant cellcycle arrest in the $\mathrm{G} 2$ phase $(\mathrm{ME}-1: P<0.001$ at $48 \mathrm{~h}$, $P<0.05$ at $72 \mathrm{~h}$; OCl-AML3: $P<0.01$ at $24 \mathrm{~h}, P<0.05$ at 48 and 72 h; KG-1: $P<0.001$ at $24 \mathrm{~h}, P<0.05$ at $48 \mathrm{~h}, P<0.001$ at $72 \mathrm{~h}$ ) (Figure $3 \mathrm{k}$ and Supplementary Figure 2f), the G1 phase (MOLM-14: $P<0.001$ at $72 \mathrm{~h}$ ) (Figure $3 \mathrm{k}$ ) or the $\mathrm{S}$ phase (NB4: $P<0.001$ at $24 \mathrm{~h}, P<0.01$ at 48 and $72 \mathrm{~h}$ ) (Supplementary Figure 2f).

MiR-128a expression was upregulated in myeloid leukemic cells. To further clarify Lin28A downregulation in AML, we analyzed its regulator, miR-128a. ${ }^{28} \mathrm{We}$ evaluated miR-128a expression in the same cohort of $\mathrm{AML}$ patients and in the $A M L$ cell line panel previously examined for Lin28A, observing a significant overexpression of this microRNA compared with healthy subjects (Figure 4a). Stratifying AML cases for morphologic features, we found, at variance with Lin28A, elevated expression levels of miR-128a in AML with maturation and acute promyelocytic leukemia (APL) cases compared with controls (Figure 4b). Furthermore, considering patients for their gene mutations, we found a significantly higher expression of miR-128a in patients with FLT3, PML/RARa and other genomic alterations (Figure 4c).

Our results show different expression pattern of $m i R-128 a$ in MOLM-14 and AML samples, both carrying FLT3-ITD (Figures $4 \mathrm{a}$ and $\mathrm{c}$ ). Matsuo et al. ${ }^{38}$ demonstrated that MOLM-14, along with FLT3-ITD, carries a series of genotypic aberrancies, such as the insertion ins $(11 ; 9)$ with the fusion hybrid MLL-AF9. ${ }^{38}$ This complex pattern could justify the partially divergent behavior of MOLM-14 as compared with fresh AML samples. Moreover, we also evaluated, by qRTPCR, miR-128a expression during macrophage- and granulocytic-like differentiation detecting a significant 

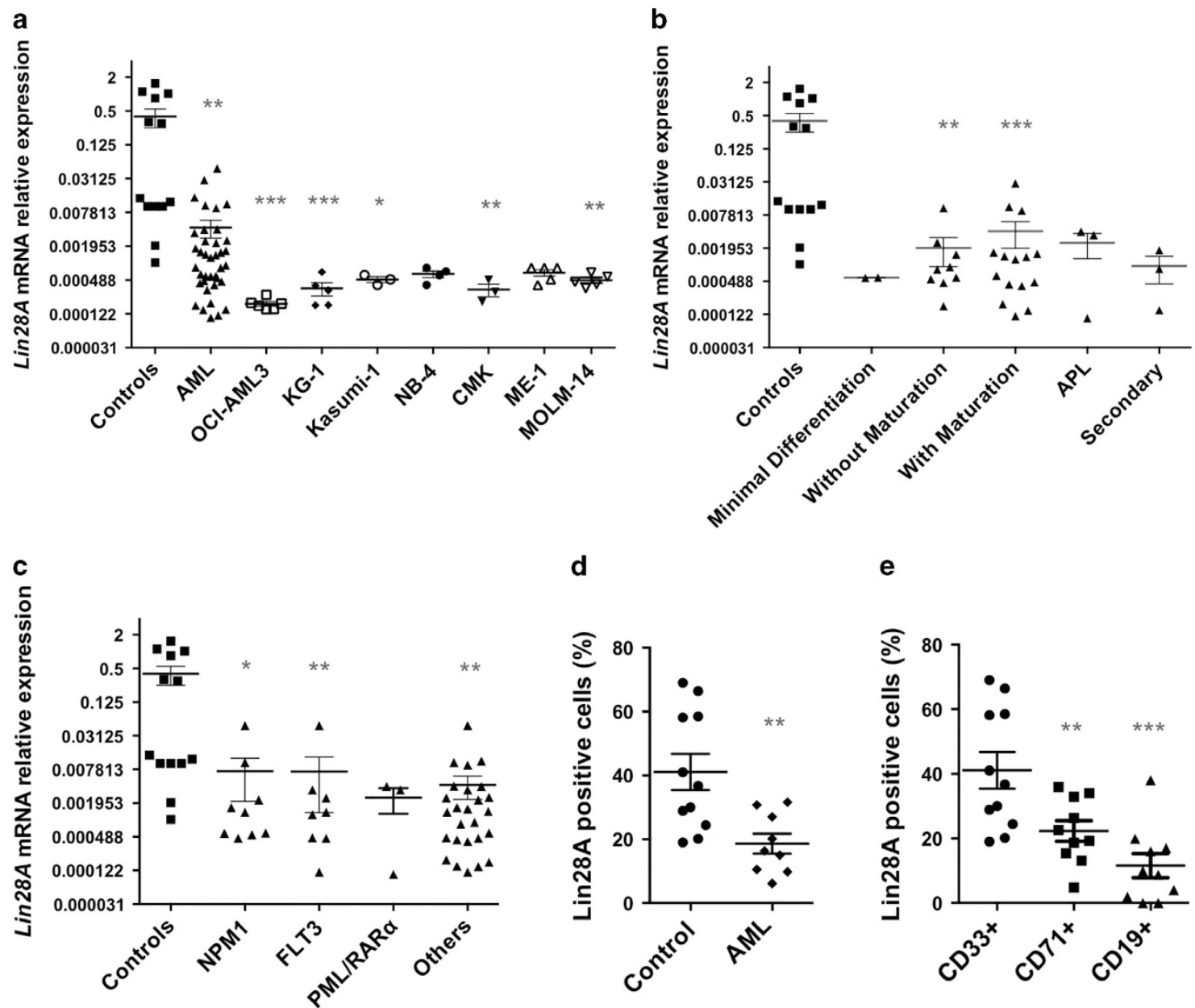

d

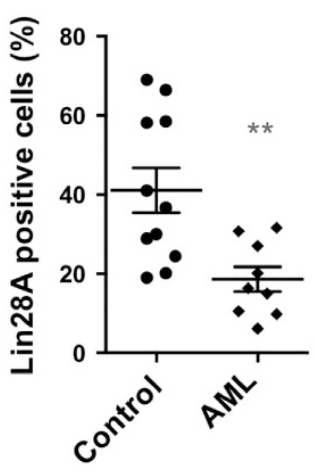

e

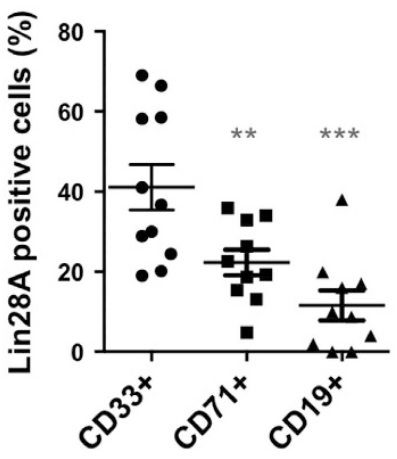

Figure 1 Lin28A expression in leukemic blasts from AML patients. (a) qRT-PCR of Lin28A in 13 healthy controls, 38 AML patients and 7 AML cell lines (OCl-AML3, KG-1, Kasumi-1, NB4, CMK, ME-1 and MOLM-14); ABL1 was used for normalization. Relative values were calculated on the basis of the $\triangle C p$ method. Results are shown as mean \pm S.E.M. (b) Expression of Lin28A mRNA in AML patients stratified for morphologic features (with minimal differentiation, $n=2$; without maturation, $n=9$; with maturation including: $n=3$ with maturation, $n=10$ acute myelomonocytic leukemia, $n=2$ acute monoblastic/monocytic leukemia; APL, $n=3$; secondary AML, $n=3$ ) was compared with 13 healthy controls. Results are shown as mean \pm S.E.M. (c) Expression of Lin28A mRNA in AML patients with specific mutations (NPM1, $n=9$; FLT3, $n=8$; PML/RAR $\alpha, n=3$ or with other alterations, $n=26$ ) was compared with 13 healthy controls. Results are shown as mean \pm S.E.M. (d) Percentage of Lin28A+ cells in 11 BM healthy controls and 9 AML patients, by cytofluorimetric analysis. (e) Percentage of Lin28A+ cells in normal myeloid (CD34+ CD45+ CD33+), erythroid (CD34+ CD45+ CD71+) and lymphoid (CD34+ CD45+ CD19+) precursors, by cytofluorimetric analysis. Statistically significant analyses are indicated by asterisks: ${ }^{*} P<0.05,{ }^{\star *} P<0.01$ and ${ }^{\star \star *} P<0.001$

downregulation of this microRNA from 24 to $72 \mathrm{~h}$ in treated cell lines (Figure 4d and Supplementary Figure 3a). To determine the role of miR-128a in myeloid differentiation, we transiently transfected OCl-AML3 and ME-1 cells with anti-miR-128a. After transfection, the inhibition of miR-128a (Figure $4 \mathrm{e}$ and Supplementary Figure 4a) and the increase of ZFP36 were confirmed by qRT-PCR assay (Figure $4 \mathrm{f}$ and Supplementary Figure 4b), thus supporting a role of miR-128a in monocyte/ macrophage differentiation. Furthermore, to confirm a miR-128/Lin28A axis, we evaluated Lin28A expression after anti-miR-128a transfection, confirming its upregulation in both cell lines (Figure $4 \mathrm{~g}$ and Supplementary Figure 4c); we also observed an increase of p21 in OCl-AML3 cells (Figure 4g).

MiR-128a overexpression altered macrophage- and granulocytic-like differentiation. To examine the effect of miR-128a in AML, we overexpressed by lentiviral infection its microRNA precursor (pLKO.1_miR-128a) and, as a control, an empty vector (pLKO.1_scr) in OCI-AML3 (Supplementary Figure 5). After lentivirus infection, cells were treated with PMA to differentiate in macrophage-like cells. Although during differentiation miR-128a expression seemed to be reduced in treated cells, its levels remained significantly higher in pLKO.1_miR-128a cells than in pLKO.1_scr cells $(P<0.05$ at $24 \mathrm{~h}, P<0.01$ at $48 \mathrm{~h}$ and $72 \mathrm{~h})$ (Figure $5 \mathrm{a})$. Concurrently, Lin28A expression increased as a consequence of the induction culture, but it was significantly downregulated in OCl-AML3 infected with miR-128a ( $P<0.05$ at 24-72 h) compared with control (Figure 5b).

Overexpression of miR-128a inhibited macrophage-like differentiation markers. In fact, flow cytofluorimetric data showed a reduction of CD11b+ and CD14+ cells after 24, 48 and $72 \mathrm{~h}$ of treatment with PMA (Figures $5 \mathrm{c}-\mathrm{e}$ ) in pLKO.1_miR-128a cells compared with that in pLKO.1_scr cells $(P<0.05$ at $72 \mathrm{~h})$. These data were confirmed by morphologic analysis with May-Grünwald Giemsa staining 
a

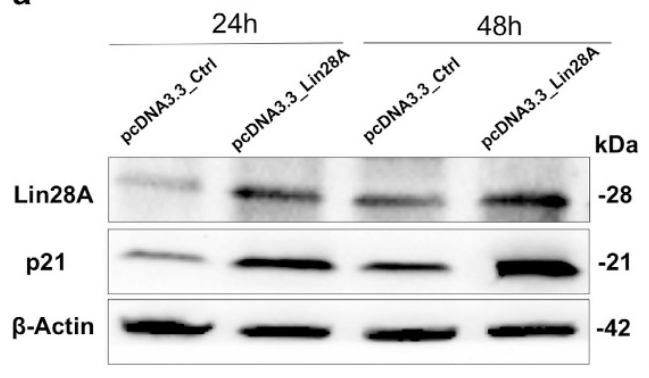

b

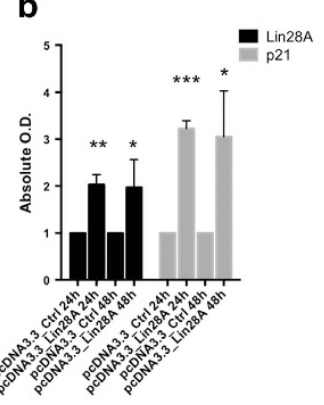

C

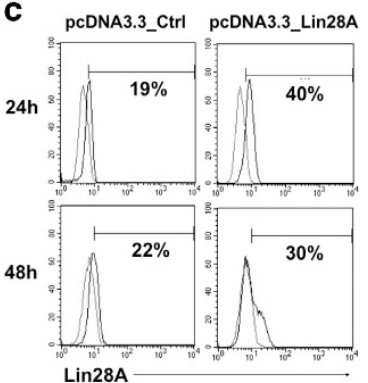

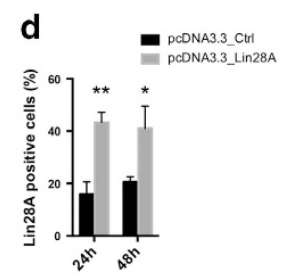
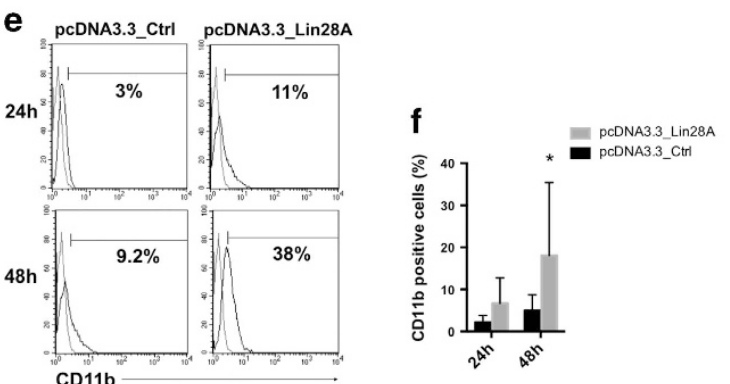

g. poDNA3.3_Ctr1 poDNA3.3_Lin28A
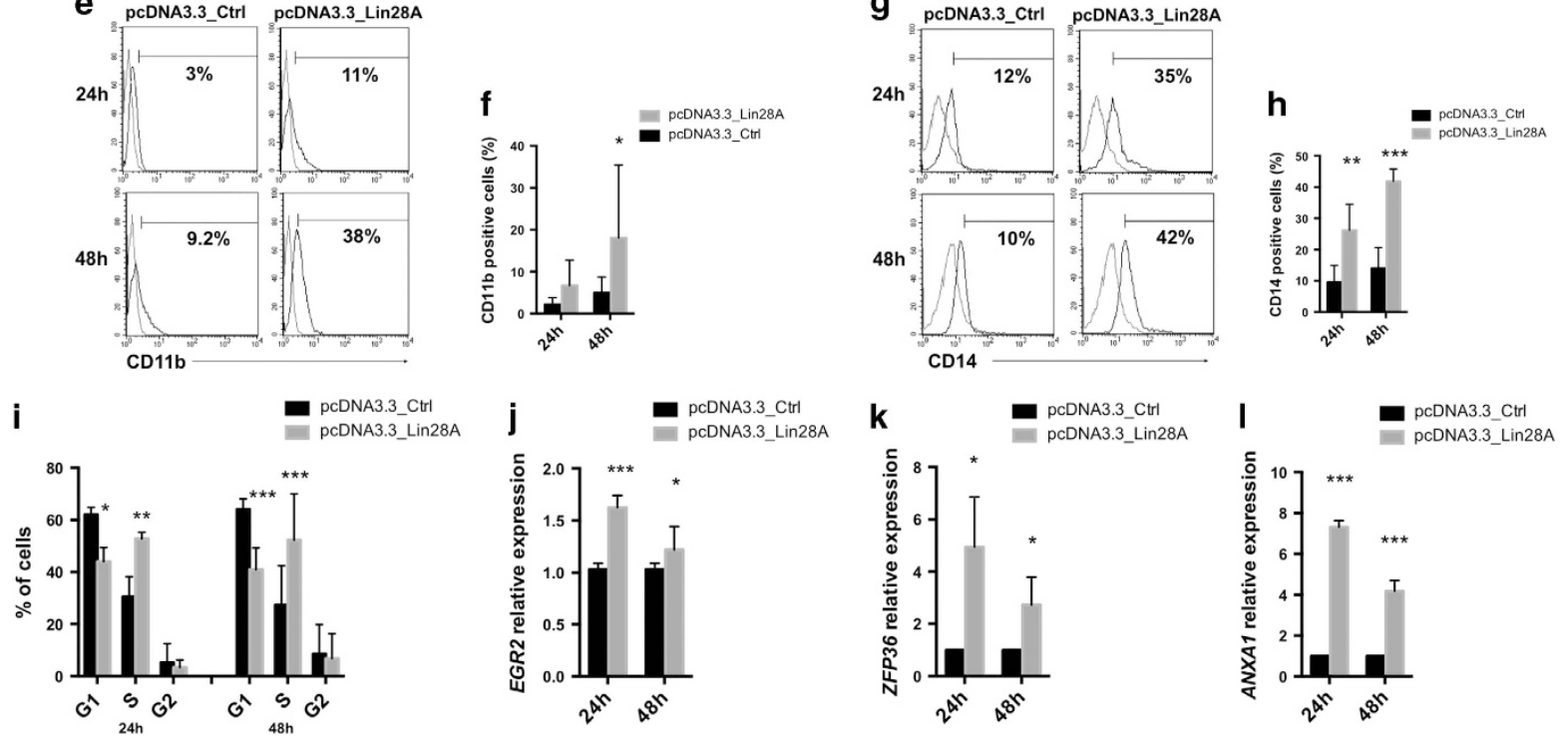

Figure 2 Overexpression of Lin28A in OCl-AML3 cell line. (a) Western blotting (WB) analysis of Lin28A, p21 and $\beta$-actin in OCl-AML3 after 24 and 48 h of transfection with pcDNA3.3_Ctrl or pcDNA3.3_Lin28A plasmids. (b) Absolute OD values of (a) were normalized to $\beta$-actin and shown as mean \pm S.D. from two independent experiments. (c) Representative cytofluorimetric analysis of percentage Lin28A+ cells in OCI-AML3 after 24 and $48 \mathrm{~h}$ of transfection with pcDNA3.3_Ctrl or pcDNA3.3_Lin28A plasmids. (d) Percentage of Lin28A+OCl-AML3 cells after 24 and $48 \mathrm{~h}$ of transfection with pcDNA3.3_Ctrl or pcDNA3.3_Lin28A plasmids, by cytofluorimetric analysis. (e) Representative cytofluorimetric analysis of CD11b+cells in OCI-AML3 after 24 and $48 \mathrm{~h}$ of transfection with pcDNA3.3_Ctrl or pcDNA3.3_Lin28A plasmids. (f) Percentage of CD11b+ OCI-AML3 cells after 24 and $48 \mathrm{~h}$ of transfection with pcDNA3.3_Ctrl or pcDNA3.3_Lin28A plasmids. (g) Representative cytofluorimetric analysis of CD14+ cells in OCI-AML3 after 24 and $48 \mathrm{~h}$ of transfection with pcDNA3.3_Ctrl or pcDNA3.3_Lin28A plasmids. (h) Percentage of CD14+ OCl-AML3 cells after 24 and $48 \mathrm{~h}$ of transfection with pcDNA3.3_Ctrl or pcDNA3.3_Lin28A plasmids, by cytofluorimetric analysis. (i) Cell-cycle analysis in OCl-AML3 after 24 and $48 \mathrm{~h}$ of transfection with pcDNA3.3_Ctrl or pcDNA3.3_Lin28A plasmids. (j-I) qRT-PCR of EGR2 (j) ZFP36 (k) and ANXA1 (I) in OCl-AML3 after 24 and $48 \mathrm{~h}$ of transfection with pcDNA3.3_Ctrl or pcDNA3.3_Lin28A plasmids. The bar graphs represented mean \pm S.D. from three independent experiments. Statistically significant analyses are indicated by asterisks: ${ }^{*} P<0.05,{ }^{* *} P<0.01$ and ${ }^{* * *} P<0.001$

of infected cells, highlighting that miR-128a overexpression led to less mature macrophage-like cells (Figure 5f). Moreover, lentiviral infection of miR-128a inhibited colony-forming activity of colony-forming unit-macrophage (CFU-M) in colony size and number (Figures $5 \mathrm{~g}$ and $\mathrm{h}$ ).

Inhibition of miR-128a improved myeloid differentiation in AML BM HSPC. Since significantly increased miR-128a expression was mainly observed in AML with maturation, we investigated how miR-128a inhibition could influence myeloid differentiation/maturation blockage. Lenti-miRZip-128a stably expresses hairpins that have anti-miRNA activity. We used BM HSPCs derived from two AML patients with maturation (myeloblastic AML3 and myelomonocyte AML2, respectively), both FLT3 mutated, and one APL patient (AML1) (Supplementary Table S1). BM HSPCs were infected with Lenti-miRZip-128a or Lenti-GFP and exposed to macrophage-like induction culture. Flow cytometric analysis showed a significant increased of CD11b and CD14 percentage of positive cells in AML HSPCs infected with Lenti-miRZip-128a compared with the control (Figures 6a and b). Lenti-miRZip-128a infection decreased the levels of mature miR-128a (Figure $6 \mathrm{c}$ ) and significantly enhanced the expression of Lin28A, EGR2, ZFP36 and ANXA1 (Figure 6d). These results demonstrated that miR-128a inhibition in AML induce myeloid differentiation.

\section{Discussion}

AMLs are clonal diseases of hematopoietic progenitor cells, characterized by marked heterogeneity in terms of phenotypic, genotypic and clinical features. ${ }^{1,2,4,39}$ In this study, we showed that Lin28A, an RNA-binding protein, ${ }^{12}$ was significantly underexpressed in AML samples without any 
a

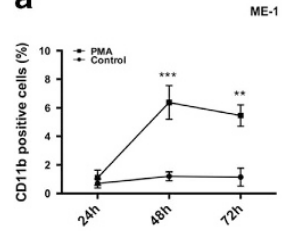

ME- 1

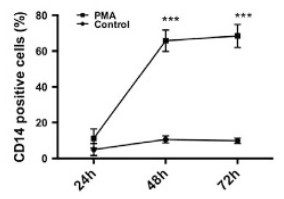

d

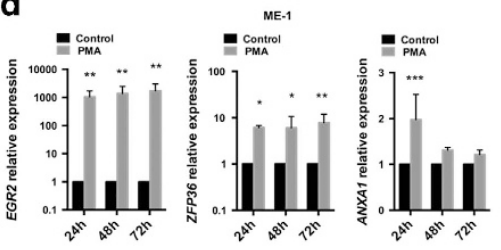

g

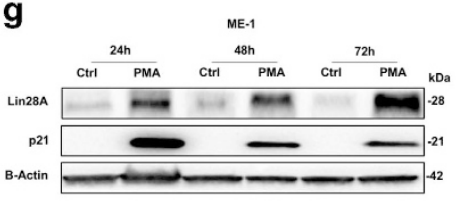

b

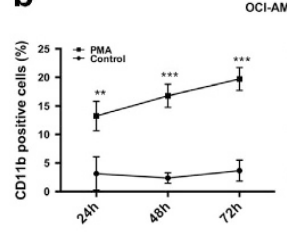

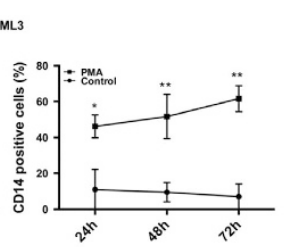

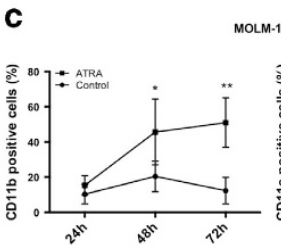

MOLM-14

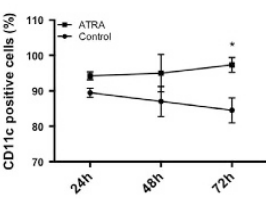

e
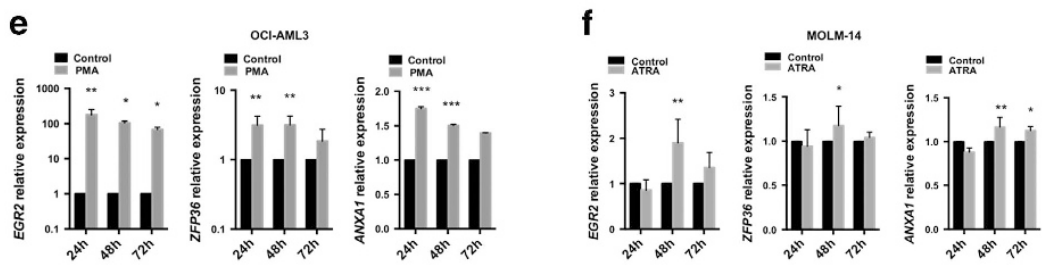

h

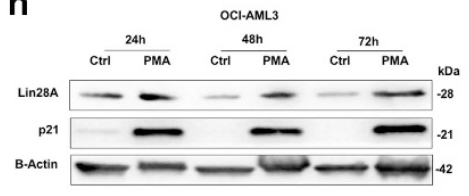

i

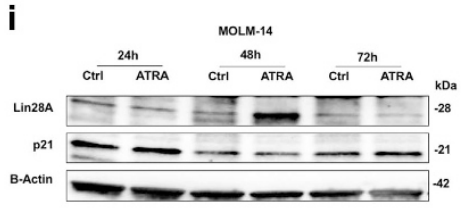

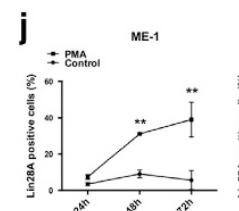
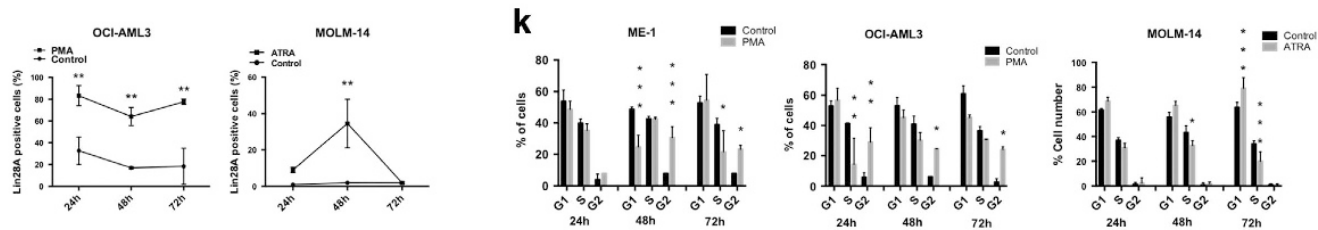

Figure 3 Lin28A upregulation during macrophage-like differentiation in AML cell lines. (a and $\mathbf{b}$ ) Percentage of CD11b+and CD14+ cells in ME-1 (a) and OCI-AML3 (b) after 24, 48 and $72 \mathrm{~h}$ of treatment with PMA, by cytofluorimetric analysis. (c) Percentage of CD11b+ and CD11c+ cells of MOLM-14 after 24,48 and $72 \mathrm{~h}$ of treatment with ATRA, by cytofluorimetric analysis. (d-f) qRT-PCR of EGR2, ZFP36 and ANXA1 in ME-1 (d), OCl-AML3 (e) and MOLM-14 (f) after 24, 48 and $72 \mathrm{~h}$ of treatment with PMA or ATRA. (g-i) Western blotting (WB) analysis of Lin28A, p21 and $\beta$-actin in ME-1 (g), OCI-AML3 (h) and MOLM-14 (i) after 24, 48 and $72 \mathrm{~h}$ of treatment with PMA. (j) Percentage of Lin28A+ ME-1, OCI-AML3 and MOLM-14 cells after 24, 48 and $72 \mathrm{~h}$ of treatment with PMA or ATRA, by cytofluorimetric analysis. (k) Cell-cycle analysis in ME-1, OCI-AML3 and MOLM-14 cells after 24,48 and $72 \mathrm{~h}$ of treatment with PMA or ATRA. The line and bar graphs represented mean \pm S.D. from three independent experiments. Statistically significant analyses are indicated by asterisks: ${ }^{*} P<0.05,{ }^{* *} P<0.01$ and ${ }^{* * *} P<0.001$

association with genotypic and phenotypic stratification. Moreover, we found a higher percentage of Lin28A+ cells in myeloid precursors compared with that in erythroid and lymphoid normal precursors, suggesting a preferential involvement of this protein in myeloid lineage differentiation.

Recently, Chaudhuri et al. ${ }^{26}$ demonstrated that the knockdown of Lin28A in mouse hematopoietic system led to myeloid cell expansion and decrease of B-cell number, thus triggering an alteration of hematopoiesis. Furthermore, its overexpression in normal HSC produced a significant reduction of total white blood cells, causing mice dead at 5 weeks, probably because of the impaired hematopoietic development. ${ }^{26}$

Our data, instead, showed that Lin28A overexpression in AML cells activated myeloid maturation. We observed, in fact, an increase of myeloid differentiation markers and a cell-cycle arrest with p21 expression augment. Literature data demonstrated that p21, a cyclin-dependent kinase inhibitor, induced cell-cycle arrest if overexpressed in progenitor cells favoring macrophage differentiation because of the accumulation of PU.1, a lineage-determining factor. ${ }^{40}$ Of importance, we also detected a significant increase of macrophage-specific genes like early growth response 2 (EGR2), an EGR protein involved in macrophage growth and differentiation, ${ }^{34,41}$ tristetraprolin (ZFP36), an anti-inflammatory and anticarcinogenic protein that is also involved in monocyte/macrophage differentiation processes and annexin $A 1$ ( $A N X A 1)$ an anti-inflammatory protein stored in the macrophage cytosol. ${ }^{37,42}$ In addition, we demonstrated that Lin28A is a positive regulator of granulocytic- and macrophage-like differentiation. In fact, we observed its significant increase simultaneously augmented different myeloid-specific markers, stimulated by ATRA or PMA treatment, in five AML cell lines with different genotype and morphology.

Previous studies reported that Lin28A is a direct target of miR-128, ${ }^{28}$ a microRNA involved in hematopoiesis. ${ }^{29,30}$ Different studies have associated $m i R-128 a$ with leukemia, showing that miR-128a belongs to a set of miRNAs with stringent specificity for AML or ALL. ${ }^{31-33}$ Moreover, miR-128a expression was found to be associated with a subgroup of AML patients with high-risk molecular features, refractoriness, relapse and death. ${ }^{31,33}$

In our study, we evaluated miR-128a expression in our cohort of AML patients. Of interest, miR-128a showed a significantly higher level in APL and AML with mature phenotypes harboring FLT3 and/or other alterations. Qian et al. $^{28}$ sustained that miR-128 directly target BMI1, CSF1, $K L F 4, L I N 28 A, N A N O G$ and SNAIL. Some of these genes are involved in self-renewal (Bmi1 and Nanog) ${ }^{43}$ and 
differentiation (CSF1 and KLF4). ${ }^{44,45}$ Similar to Lin28A, they are deregulated in AML. ${ }^{45-47} \mathrm{KLF} 4$, for example, a lineagespecific transcriptor factor that promotes monocyte differentiation is downregulated in undifferentiated subtype M0 and in
FLT3-ITD and NPM1-mutant AML. ${ }^{45}$ BMI1, instead, a polycomb group protein involved in self-renewal is overexpressed in different AML subtypes. ${ }^{46}$ Given that gene regulation is complex and depend on different factors, ${ }^{45,48-50}$ the relative
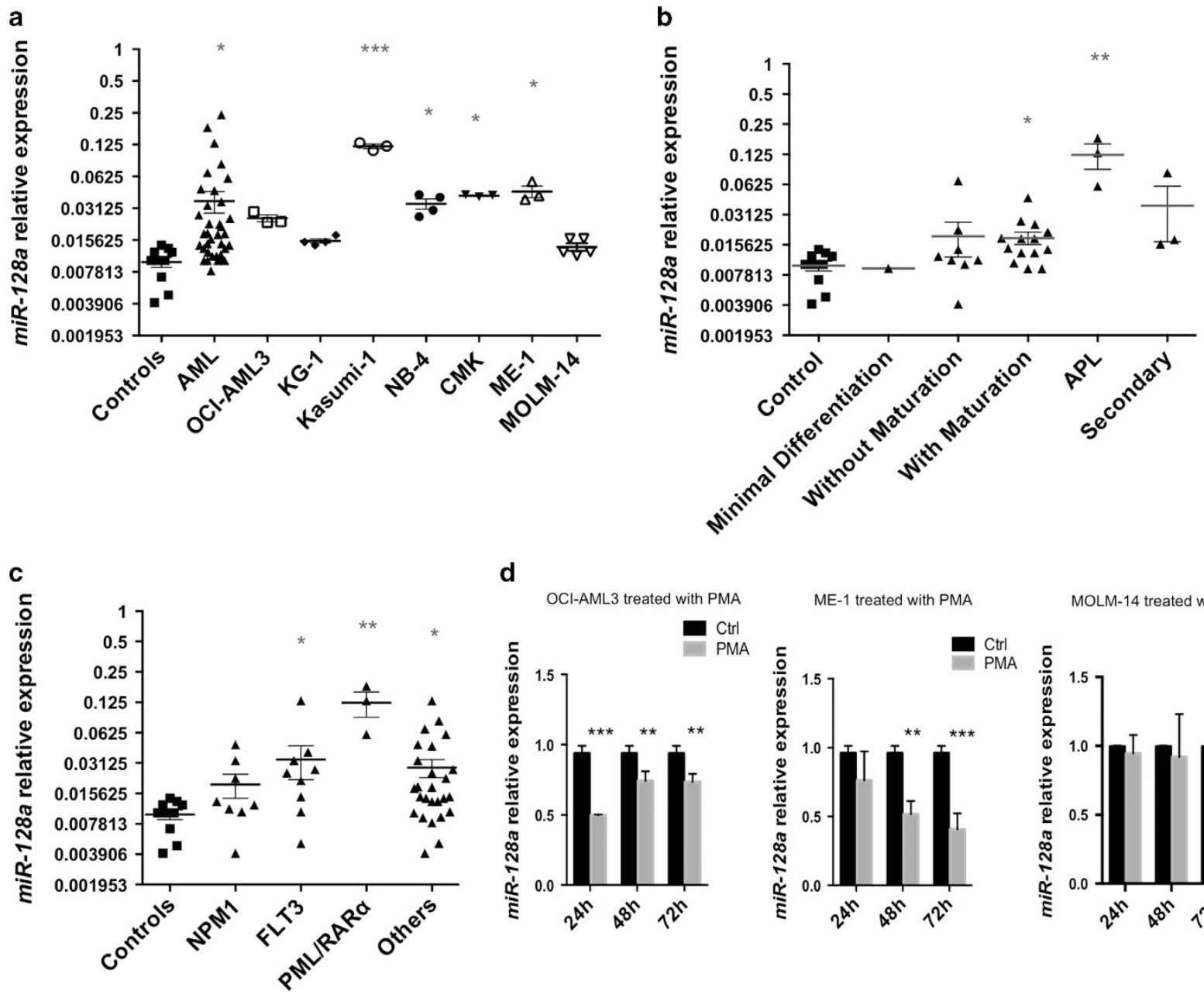

d
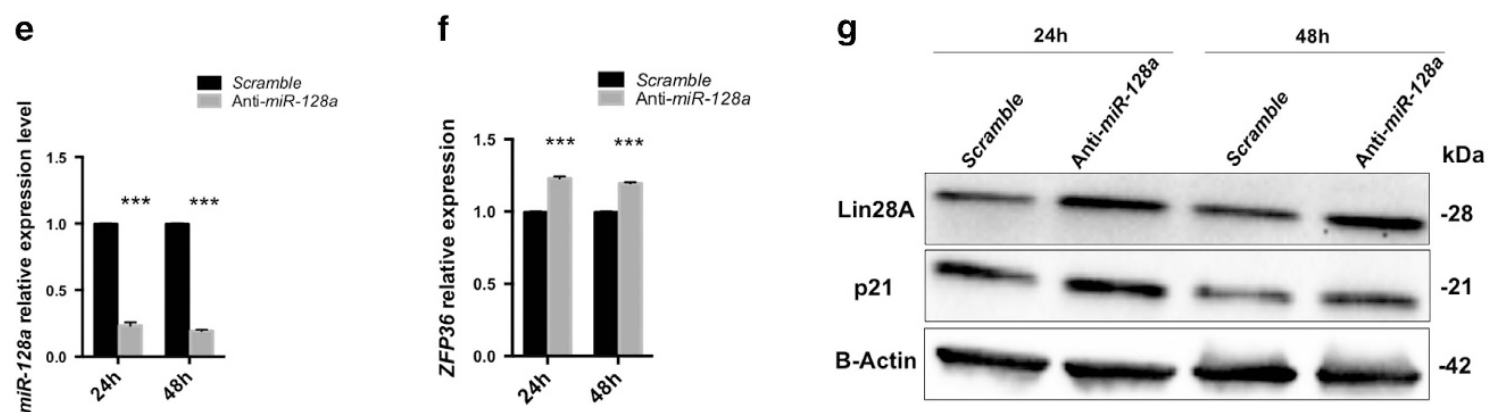

Figure 4 MiR-128a expression in leukemic blasts from AML patients and its inhibition in OCI-AML3 cell line. (a) qRT-PCR of MiR-128a in 10 healthy controls, 35 AML patients and 6 AML cell lines (OCI-AML3, KG-1, Kasumi-1, NB4, CMK, ME-1 and MOLM-14); RNU44 was used for normalization. Relative values were calculated on the basis of the $\Delta \mathrm{Cp}$ method. Results are shown as mean \pm S.E.M. (b) Expression of miR-128a in AML patients stratified for morphologic features (with minimal differentiation, $n=1$; without maturation, $n=8$; with maturation including: $n=3$ with maturation, $n=9$ acute myelomonocytic leukemia, $n=2$ acute monoblastic/monocytic leukemia; APL, $n=3$; secondary AML, $n=3$ ) was compared with 10 healthy controls. Results are shown as mean \pm S.E.M. (c) Expression of miR-128a in AML patients with specific mutations (NPM1, $n=8$, FLT3, $n=9$ or with other alterations, $n=26$ ) was compared with 10 healthy controls. Results are shown as mean \pm S.E.M. (d) qRT-PCR of miR-128a in OCI-AML3, ME-1 and MOLM-14 cells after 24,48 and $72 \mathrm{~h}$ of treatment with PMA or ATRA. The bar graphs represented mean \pm S.D. from three independent experiments. (e and f) qRT-PCR of miR-128a (e) and ZFP36 (f) in OCI-AML3 after 24 and $48 \mathrm{~h}$ of scramble or anti-miR-128a transfection. The bar graphs represented mean \pm S.D. from three independent experiments. (g) Western blotting (WB) analysis of Lin28A, p21 and $\beta$-actin in OCl-AML3 after 24 and $48 \mathrm{~h}$ of transfection with scramble or anti-miR-128a. Statistically significant analyses are indicated by asterisks: ${ }^{*} P<0.05,{ }^{* *} P<0.01$ and ${ }^{* *} P<0.001$ 
a
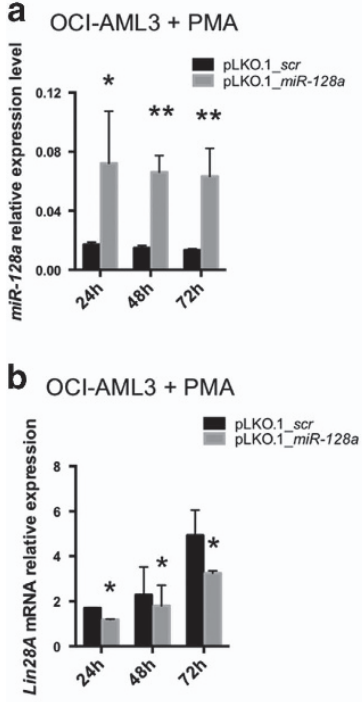

f

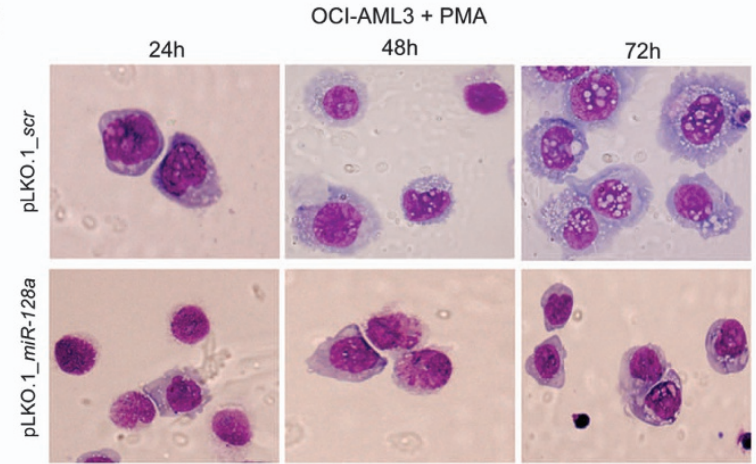

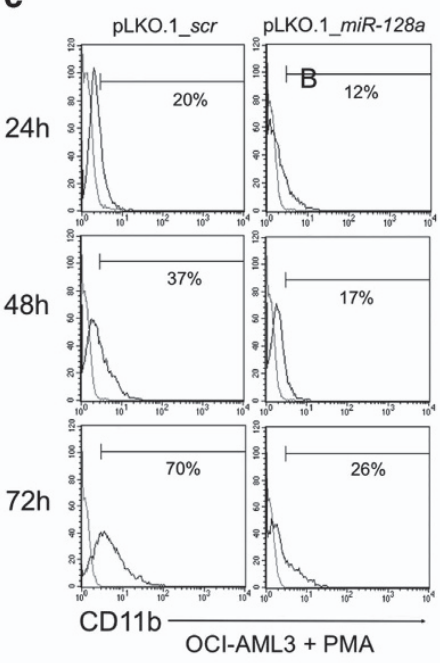

d

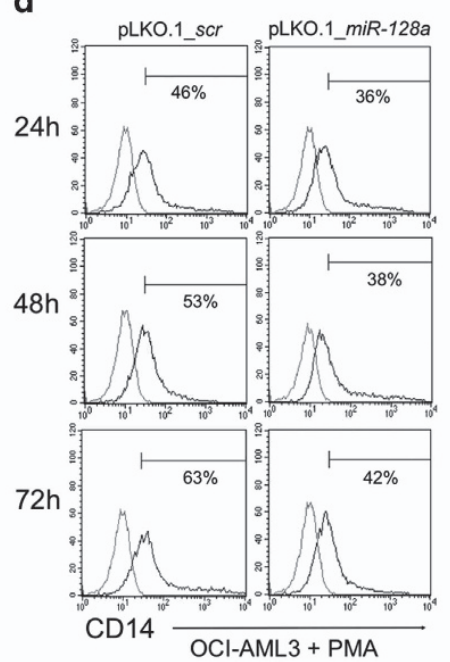

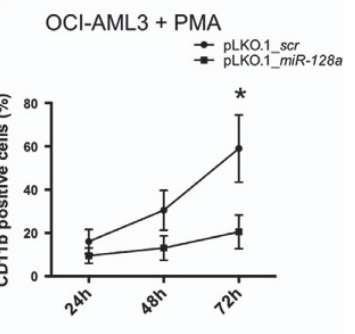

$\mathrm{OCI}-\mathrm{AML} 3+\mathrm{PMA}$ $\div$ PLKO.1_miR-128a

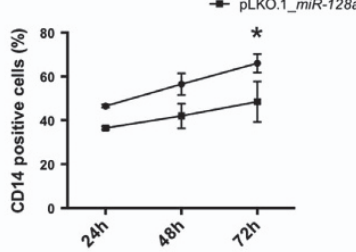

g

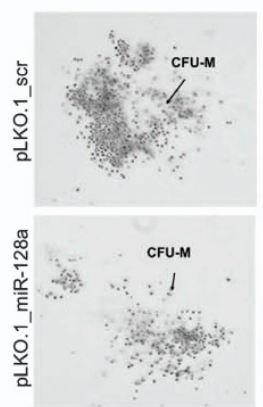

h

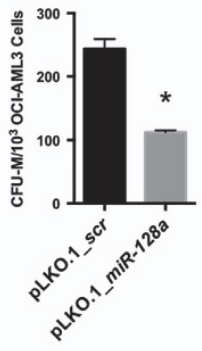

Figure 5 MiR-128a overexpression in OCl-AML3 cell line. (a and $\mathbf{b})$ qRT-PCR of miR-128a (a) and Lin28A (b) in OCl-AML3 infected with pLKO.1_scr or pLKO.1_miR-128a after 24, 48 and $72 \mathrm{~h}$ of PMA treatment. (c and d) Representative histogram plots of CD11b+ (c) and CD14+ cells (d) in OCI-AML3 infected with pLKO.1_scr or pLKO.1_miR-128a after 24, 48 and $72 \mathrm{~h}$ of PMA treatment. (e) Percentage of CD11b+ and CD14+ OCl-AML3 cells infected with pLKO.1_scr or pLKO.1_miR-128a after 24, 48 and $72 \mathrm{~h}$ of PMA treatment, by cytofluorimetric analysis. (f) May-Grünwald Giemsa staining of OCI-AML3 infected with pLKO.1_scr or pLKO.1_miR-128a after 24, 48 and $72 \mathrm{~h}$ of PMA treatment. (g) Colony-forming assay of OCl-AML3 after infection with pLKO.1_scr or pLKO.1_miR-128a. Colonies were observed at day 14 of the semisolid culture under $\times 20$ magnification. (h) Count of CFU-M colonies. The line and bar graphs represented mean \pm S.D. from three independent experiments. Statistically significant analyses are indicated by asterisks: ${ }^{*} P<0.05$ and ${ }^{* *} P<0.01$

upregulation of miR-128 could not be sufficient to repress all these genes.

Various microRNAs have an important role in acute myeloid leukemogenesis, ${ }^{50,51}$ because of their role in the different stages of hematopoiesis. ${ }^{29,52}$ MiR-125b, for example, is overexpressed in certain types of AML (C/EBPa, t(2;11)(p21;q23), GATA1) and inhibits myeloid differentiation. ${ }^{50,53}$ Moreover, its overexpression causes a dose-dependent myeloproliferative disorder progressing to a lethal myeloid leukemia in mice. ${ }^{50}$ MiR-181 family, instead, was found abnormally upregulated in AML patients, with $t(8 ; 21)$ and $t(15 ; 17)$ inhibiting granulocyticand macrophage-like differentiations. ${ }^{54}$ Here, we demonstrated that miR-128a was downregulated during induced granulocyteand macrophage-like differentiation of AML cell lines. Moreover, we showed a reduction of Lin28A- and myeloid-specific marker expression following enforced miR-128a expression, in spite of PMA treatment in vitro. Conversely, miR-128a transient inhibition in two cell lines enhanced myeloid maturation and Lin28A overexpression. Given the higher expression of
miR-128a in AML with mature phenotypes and with FLT3 or $P M L / R A R a$ alterations, we decided to inhibit miR-128a maturation in leukemic cells of these subsets of patients to stimulate further propensity to cell differentiation. In fact, LentimiRZip-128a infection remarkably repressed miR-128a and improved granulocytic/macrophage-like differentiation in BM-derived AML blasts. Finally, we detected an augment of Lin28A in all infected AML blasts patients, while an increase of macrophage-specific genes occurred only in AML with FLT3 mutation and mature phenotypes.

Specific microRNAs with established oncogenic functions, such as miR-155, miR-125b, miR-181 and miR-128a, appear to be associated with particular AML subtypes. ${ }^{31,50,55}$ Selected sets of microRNAs could be used as a target therapy tailored to specific biological and molecular features of AML. ${ }^{50}$ In particular, we hypothesize that in $\mathrm{AML}$ subtypes with $\mathrm{t}(8 ; 21)$ and inv16, differentiation block could be released by $\mathrm{miR}-128 \mathrm{a}$ knockdown in combination with differentiation agents. In this setting, we previously demonstrated that G-CSF treatment of a 

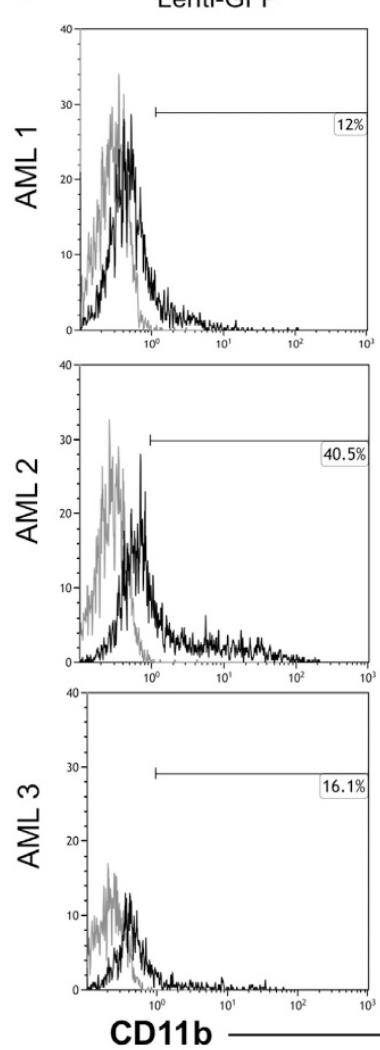

C

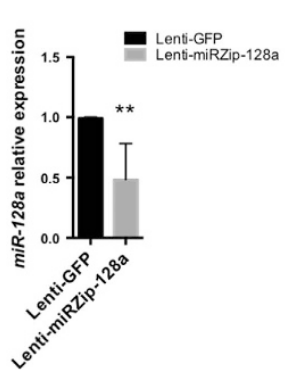

d
Lenti-miRZip-128a
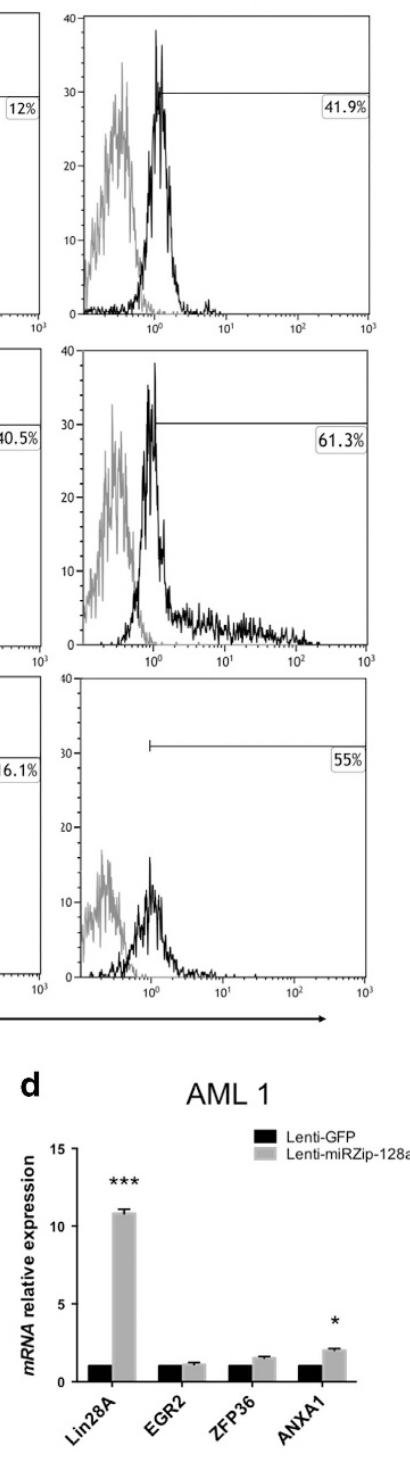

b
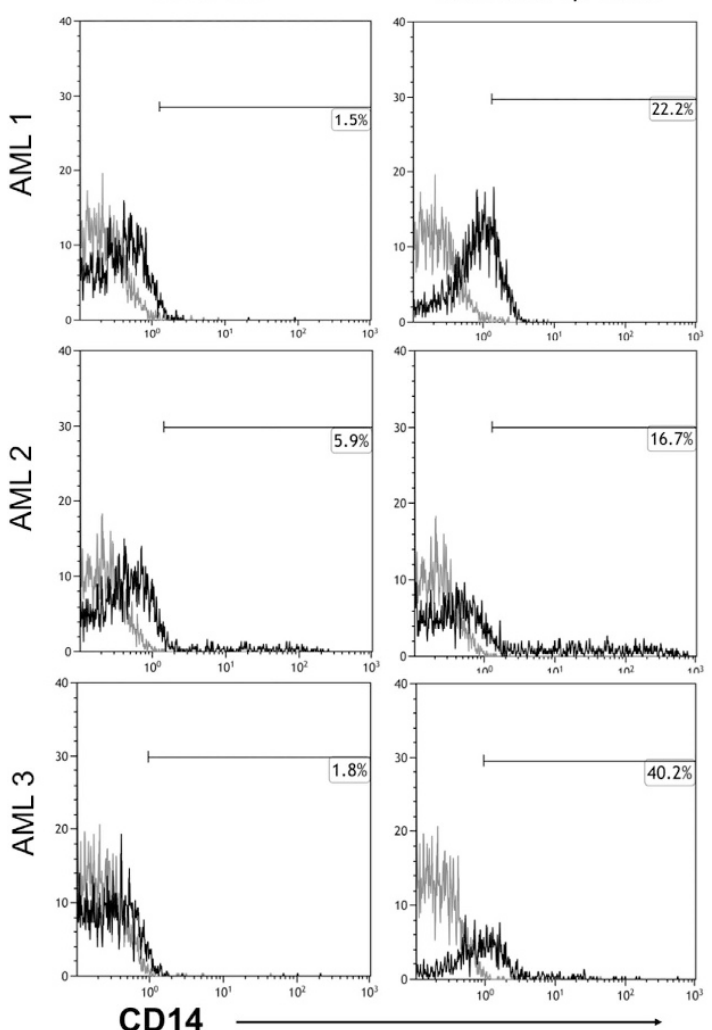

AML 2

AML 3
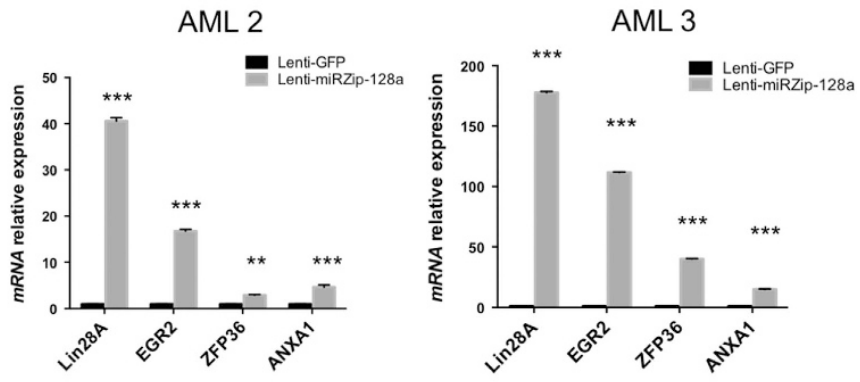

Figure 6 Inhibition of miR-128a in leukemic cells from AML patients. (a and $\mathbf{b})$ Percentage of CD11b+ (a) and CD14+ cells (b) from three AML patients (AML1, AML2 and AML3) infected with Lenti-GFP or Lenti-miRZip-128a after 3 days of macrophage-like induction culture, by cytofluorimetric analysis. (c) qRT-PCR of miR-128a in AML patients infected with Lenti-GFP or Lenti-miRZip-128a. (d) qRT-PCR of Lin28A, EGR2, ZFP36 and ANXA1 in AML patients infected with Lenti-GFP or Lenti-miRZip-128a after 3 days of macrophage-like induction culture. Statistically significant analyses are indicated by asterisks: ${ }^{*} P<0.05,{ }^{* *} P<0.01$ and ${ }^{* *} P<0.001$

patient with $\mathrm{t}(8 ; 21)$ AML led to complete remission. ${ }^{56}$ Moreover, the combined inhibition of miR-128a and miR-155 could be evaluated as a therapeutic option in high -isk AML patients harboring FLT3 mutation.

In conclusion, we revealed a new regulatory axis $m i R-128 a$ / Lin28A that affects hematopoiesis, favoring AML development. Our experiments suggest that the inhibition of $m i R-128 a$ could provide a new strategy for AML therapy.

\section{Materials and Methods}

Human samples. BM samples were obtained from $40 \mathrm{AML}$ patients (37 de novo and 3 secondary $\mathrm{AML}$ ) at the time of diagnosis from the IRCCS CROB Hospital. The clinical and biological characteristics of AML patients are summarized in Supplementary Table S1. All patients gave written informed consent according to the Declaration of Helsinki. BM and peripheral blood samples of 13 healthy donors were also obtained from San Luigi Gonzaga Hospital of Turin. CD34+ cells of all samples were purified from mononuclear cells with a CD34 Microbead Kit (Miltenyi Biotec, Auburn, CA, USA). The purity of immunoselected cells routinely ranged between 90 and $95 \%$ and it was assessed by flow cytometric analysis using an allophycocyanin (APC) anti-CD34 (BD Pharmingen, San Jose, CA, USA).

Cell lines. The human AML cell lines, OCI-AML3, KG-1, Kasumi-1, NB4, CMK, ME-1 and MOLM-14, were acquired from American Type Culture Collection (Rockville, MD, USA) or Deutsche Sammlung von Mikroorganismen und Zellkulturen (Braunschweig, Germany). AML cell line characteristics were reported in Supplementary Table S2. OCI-AML3 cells were maintained in DMEM medium (Gibco, Life Technologies, Carlsbad, CA, USA) supplemented with 20\% fetal bovine serum (FBS) (Gibco), $1 \%$ of penicillin-streptomycin (Gibco) and $4 \mathrm{mM}$ of 
L-glutamine (Gibco). KG-1, Kasumi-1, NB4, CMK, ME-1 and MOLM-14 cells were maintained in RPMl-1640 medium (Gibco) supplemented with $10 \% \mathrm{FBS}, 1 \%$ of penicillin-streptomycin (Gibco) and $2 \mathrm{mM}$ of L-glutamine (Gibco). Cells were grown at $37^{\circ} \mathrm{C}$ in $5 \% \mathrm{CO}_{2}$.

Cell line differentiation assessment. Macrophage- or granulocytic-like differentiation was induced in OCl-AML3 and ME-1 cell lines with PMA (SigmaAldrich, St. Louis, MO, USA) at $100 \mathrm{nM}$ concentration and in NB4 and KG-1 cells with ATRA (Sigma-Aldrich) at $10 \mu \mathrm{M}$ concentration. Cells were seeded at $400000 /$ $\mathrm{ml}$ and were harvested after 24,48 and $72 \mathrm{~h}$ to evaluate cell differentiation.

Induction culture of AML CD34+ cells. AML CD34+ cells were cultured in StemMACS HSC Expansion medium with StemMACS HSC Expansion Cocktail 1x (Miltenyi Biotec). To induce macrophage-like differentiation $20 \mathrm{ng} / \mathrm{ml} \mathrm{M}$-CSF and $1 \mathrm{ng} / \mathrm{ml} \mathrm{IL}-6$ (Miltenyi Biotec) were used.

Flow cytometry. Cytofluorimetric analysis of intracellular Lin28A protein levels was performed after fixation and permeabilization with the IntraCell Kit (Immunostep, Salamanca, Spain) followed by labeling with Lin28A (Cell Signaling Technology, Danvers, MA, USA) or its isotypic control (Cell Signaling Technology) in $11 \mathrm{BM}$ healthy subjects and $9 \mathrm{AML}$ patients. Lin28A protein expression was also evaluated in myeloid, lymphoid and erythroid precursors of CD34+ cells of healthy subjects by using the following fluorochrome-conjugated monoclonal antibodies and their specific isotypic controls: peridin chlorophyll (PerCP) anti-CD45, phycoerythrin (PE) anti-CD33, PE anti-CD19 and PE anti-CD71 (BD Pharmingen). The expression of myeloid-specific antigens CD14, CD11b and CD15 on cell surface was determined by direct immunofluorescent staining with the following fluorochromeconjugated monoclonal antibodies and their specific isotypic controls: APC antiCD14, PE anti-CD11b, PE anti-CD11c and PerCP anti-CD15 (BD Pharmingen). For cell-cycle analysis, cells were fixed and permeabilized, and then labeled with $\mathrm{Pl} / \mathrm{RN}$ ase staining solution for $30 \mathrm{~min}$. Cells were acquired by FACS Calibur (BD) and analysis was performed using the ModFit LT Software (Verity Software House, Topsham, ME, USA).

In vitro transfection of $\mathrm{AML}$ cell lines. Lin28A transfections were performed in OCl-AML3 by using Lipofectamine 2000 (Life Technologies, Carlsbad, CA, USA) in accordance with the manufacturer's procedure. Transient transfection of anti-miR-128a molecule (300 pmol) and negative control (Ambion, Applied Biosistem, Foster City, CA, USA) was accomplished in OCI-AML3 and ME-1 cell lines with Lipofectamine RNAi Max (Life Technologies) in accordance with the manufacturer's procedure.

RNA isolation and qRT-PCR for mRNA and miRNA quantification. Mononuclear cells were obtained by Ficoll-Paque gradient centrifugation. Total RNA was extracted using Trizol reagent (Life Technologies) according to the manufacturer's instructions. Reverse transcription was performed using $1 \mu \mathrm{g}$ of total RNA from each sample by High Capacity cDNA Reverse Transcription Kit (Applied Biosistem, Foster City, CA, USA). qRT-PCR was performed as described previously. ${ }^{57}$ Simultaneous quantification of $A B L 1$ mRNA was used as a reference for mRNA TaqMan assay data normalization. miR-128 expression was normalized on RNU44. The comparative cycle threshold (Ct) method for relative quantification of mRNA and miRNA expression (User Bulletin No. 2; Applied Biosystems) was used to determine transcript levels.

Western blotting. Cells were lysed as reported previously. ${ }^{58}$ Total proteins were extracted from AML cell lines. Equal amount of protein extract $(60 \mu \mathrm{g})$ was transferred to polyvinylidene difluoride membranes (Bio-Rad, Hercules, CA, USA). The membranes were blocked for $1 \mathrm{~h}$ with $5 \%$ milk (Sigma-Aldrich) at room temperature, and then incubated with primary antibodies directed toward Lin28A (Santa Cruz Biotechnology, Santa Cruz, CA, USA), p21 (Merck Millipore, Billerica, MA, USA) and $\beta$-actin (Sigma-Aldrich), followed by incubation with horseradish peroxidase-conjugated secondary antibodies (Bio-Rad). Protein bands were visualized and quantified as described previously. ${ }^{59}$

Lentivirus production and infection. MiR-128a expression vector were made by cloning $\sim 60 \mathrm{bp} 5^{\prime}$ and $3^{\prime}$ of the pre-miRNA into the multiple cloning site for pLKO.1 (Addgene, Cambridge, MA, USA). Lenti_GFP control and Lenti-miRZip128a were purchased by System Biosciences (Palo Alto, CA, USA). The virus packaging was performed according to the manufacturer's instructions. The virus particles (lenti_128a, lenti_GFP control and Lenti-miRZip-128a) were harvested and concentrated using PEG-it Virus Precipitation Solution (System Biosciences). Virus titer was determined in 293TN cells using the global Ultrarapid Lentiviral Titer Kit (System Biosciences). For transduction, AML primary cells and OCI-AML3 were seeded onto 6-well plates at 800000 cells per ml. Cells were infected with lentiviral stocks at an MOI of 5 in the presence of polybrene. AML primary cells were sorted for the expression of GFP using cell sorter MoFlo Atrios (Beckman Coulter, Brea, CA, USA). OCI-AML3 cells were maintained with puromycin $0.5 \mu \mathrm{g} / \mathrm{ml}$.

Colony-forming assay. OCl-AML3 cells infected with pLKO.1_SCr or pLKO.1_miR-128a were cultured in 35mm dishes in MethoCult Classic (Stem Cell Technologies, Vancouver, BC, Canada) according to the manufacturer's instruction. CFU-M were visualized, measured and counted after being cultured in incubator at $37^{\circ} \mathrm{C}$ for 14 days.

May-Grünwald Giemsa staining. OCl-AML3 cells infected with pLKO.1_scr or pLKO.1_miR-128a were harvested at 24, 48 and $72 \mathrm{~h}$ after PMA treatment and stained with May-Grünwald for $5 \mathrm{~min}$ and Giemsa for $30 \mathrm{~min}$. The cell smears were washed with water, air-dried and observed under optical microscopy (Leica, Wetzlar, Germany).

Statistical analysis. Results are shown as mean \pm S.D. or S.E.M. MannWhitney U-test was used to analyze two group comparisons (protein expression qRT-PCR). Analyses of multiple groups (qRT-PCR of Lin28A and miR-128 in patients and cell lines, Lin28A data set analysis) were performed by Dunn's multiple comparisons test after one-way ANOVA with Kruskal-Wallis test. Cytofluorimetric analyses (time course) and qRT-PCR at different time points were carried out by two-way ANOVA followed by post hoc multiple comparisons using Sidak's test. For all tests, a $P$-value $<0.05$ was taken as statistically significant.

\section{Conflict of Interest}

The authors declare no conflict of interest.

Acknowledgements. This work was supported by Italian ministry of Health, Current Research Funds for IRCCS (CUP E66J12000230001).

1. Papaemmanuil E, Gerstung M, Bullinger L, Gaidzik VI, Paschka P, Roberts ND et al. Genomic classification and prognosis in acute myeloid leukemia. N Engl J Med 2016; 374: 2209-2221.

2. Dohner H, Weisdorf DJ, Bloomfield CD. Acute myeloid leukemia. N Engl J Med 2015; 373: 1136-1152.

3. De Kouchkovsky I, Abdul-Hay M. Acute myeloid leukemia: a comprehensive review and 2016 update. Blood Cancer J 2016; 6: e441.

4. Arber DA, Orazi A, Hasserjian R, Thiele J, Borowitz MJ, Le Beau MM et al. The 2016 revision to the World Health Organization classification of myeloid neoplasms and acute leukemia. Blood 2016; 127: 2391-2405.

5. Fukushima N, Minami Y, Kakiuchi S, Kuwatsuka Y, Hayakawa F, Jamieson C et al. Smallmolecule Hedgehog inhibitor attenuates the leukemia-initiation potential of acute myeloid leukemia cells. Cancer Sci 2016; 107: 1422-1429.

6. Lu FL, Yu CC, Chiu HH, Liu HE, Chen SY, Lin S et al. Sonic hedgehog antagonists induce cell death in acute myeloid leukemia cells with the presence of lipopolysaccharides, tumor necrosis factor-alpha, or interferons. Invest New Drugs 2013; 31: 823-832.

7. Chang E, Ganguly S, Rajkhowa T, Gocke CD, Levis M, Konig H. The combination of FLT3 and DNA methyltransferase inhibition is synergistically cytotoxic to FLT3/ITD acute myeloid leukemia cells. Leukemia 2016; 30: 1025-1032.

8. Taskesen E, Staal FJ, Reinders MJ. An integrated approach of gene expression and DNAmethylation profiles of WNT signaling genes uncovers novel prognostic markers in acute myeloid leukemia. BMC Bioinform 2015; 16(Suppl 4): S4.

9. Ye Q, Jiang J, Zhan G, Yan W, Huang L, Hu Y et al. Small molecule activation of NOTCH signaling inhibits acute myeloid leukemia. Scientific Rep 2016; 6: 26510.

10. Takam Kamga P, Bassi G, Cassaro A, Midolo M, Di Trapani M, Gatti A et al. Notch signalling drives bone marrow stromal cell-mediated chemoresistance in acute myeloid leukemia. Oncotarget 2016; 7: 21713-21727.

11. Gu $Y$, Masiero $M$, Banham $A H$. Notch signaling: its roles and therapeutic potential in hematological malignancies. Oncotarget 2016; 7: 29804-29823.

12. Jiang S, Baltimore D. RNA-binding protein Lin28 in cancer and immunity. Cancer Lett 2016 375: 108-113.

13. Zhou J, Ng SB, Chng WJ. LIN28/LIN28B: an emerging oncogenic driver in cancer stem cells. Int J Biochem Cell Biol 2013; 45: 973-978. 
14. Shyh-Chang N, Daley GQ. Lin28: primal regulator of growth and metabolism in stem cells. Cell Stem Cell 2013; 12: 395-406.

15. Zhong X, Li N, Liang S, Huang Q, Coukos G, Zhang L. Identification of microRNAs regulating reprogramming factor LIN28 in embryonic stem cells and cancer cells. J Biol Chem 2010; 285: 41961-41971

16. Yu J, Vodyanik MA, Smuga-Otto K, Antosiewicz-Bourget J, Frane JL, Tian S et al. Induced pluripotent stem cell lines derived from human somatic cells. Science 2007; 318: 1917-1920.

17. Glisovic T, Bachorik JL, Yong J, Dreyfuss G. RNA-binding proteins and post-transcriptional gene regulation. FEBS Lett 2008; 582: 1977-1986.

18. Wilbert ML, Huelga SC, Kapeli K, Stark TJ, Liang TY, Chen SX et al. LIN28 binds messenger RNAs at GGAGA motifs and regulates splicing factor abundance. Mol Cell 2012; 48 : 195-206.

19. Hafner M, Max KE, Bandaru P, Morozov P, Gerstberger S, Brown M et al. Identification of mRNAs bound and regulated by human LIN28 proteins and molecular requirements for RNA recognition. RNA 2013; 19: 613-626.

20. Lukong KE, Chang KW, Khandjian EW, Richard S. RNA-binding proteins in human genetic disease. Trends Genet 2008; 24: 416-425.

21. Triboulet R, Pirouz M, Gregory RI. A single Let-7 microRNA bypasses LIN28-mediated repression. Cell Rep 2015; 13: 260-266.

22. Li X, Zhang J, Gao L, McClellan S, Finan MA, Butler TW et al. MiR-181 mediates cell differentiation by interrupting the Lin28 and let-7 feedback circuit. Cell Death Differ 2012; 19: 378-386.

23. Jiang X, Huang H, Li Z, Li Y, Wang X, Gurbuxani S et al. Blockade of miR-150 maturation by MLL-fusion/MYC/LIN-28 is required for MLL-associated leukemia. Cancer Cell 2012; 22 524-535.

24. Bousquet M, Harris MH, Zhou B, Lodish HF. MicroRNA miR-125b causes leukemia. Proc Natl Acad Sci USA 2010; 107: 21558-21563.

25. O'Connell RM, Chaudhuri AA, Rao DS, Gibson WS, Balazs AB, Baltimore D. MicroRNAs enriched in hematopoietic stem cells differentially regulate long-term hematopoietic output. Proc Natl Acad Sci USA 2010; 107: 14235-14240.

26. Chaudhuri AA, So AY, Mehta A, Minisandram A, Sinha N, Jonsson VD et al. Oncomir miR-125b regulates hematopoiesis by targeting the gene Lin28A. Proc Natl Acad Sci USA 2012; 109: 4233-4238.

27. Yuan J, Nguyen CK, Liu X, Kanellopoulou C, Muljo SA. Lin28b reprograms adult bone marrow hematopoietic progenitors to mediate fetal-like lymphopoiesis. Science 2012; 335 1195-1200.

28. Qian P, Banerjee A, Wu ZS, Zhang X, Wang H, Pandey V et al. Loss of SNAIL regulated miR-128-2 on chromosome 3p22.3 targets multiple stem cell factors to promote transformation of mammary epithelial cells. Cancer Res 2012; 72: 6036-6050.

29. Georgantas RW III, Hildreth R, Morisot S, Alder J, Liu CG, Heimfeld S et al. CD34+ hematopoietic stem-progenitor cell microRNA expression and function: a circuit diagram of differentiation control. Proc Natl Acad Sci USA 2007; 104: 2750-2755.

30. Shim J, Nam JW. The expression and functional roles of microRNAs in stem cell differentiation. BMB Rep 2016; 49: 3-10.

31. Seca H, Lima RT, Almeida GM, Sobrinho-Simoes M, Bergantim R, Guimaraes JE et al. Effect of miR-128 in DNA damage of $\mathrm{HL}-60$ acute myeloid leukemia cells. Curr Pharm Biotechnol 2014; 15: 492-502.

32. Mi S, Lu J, Sun M, Li Z, Zhang H, Neilly MB et al. MicroRNA expression signatures accurately discriminate acute lymphoblastic leukemia from acute myeloid leukemia. Proc Natl Acad Sci USA 2007; 104: 19971-19976.

33. Seca H, Almeida GM, Guimaraes JE, Vasconcelos MH. miR signatures and the role of miRs in acute myeloid leukaemia. Eur J Cancer 2010; 46: 1520-1527.

34. Pham TH, Benner C, Lichtinger M, Schwarzfischer L, Hu Y, Andreesen R et al. Dynamic epigenetic enhancer signatures reveal key transcription factors associated with monocytic differentiation states. Blood 2012; 119: e161-e171.

35. Noiret M, Hardy S, Audic Y. zfp36 expression delineates both myeloid cells and cells localized to the fusing neural folds in Xenopus tropicalis. Int J Dev Biol 2014; 58: 751-755.

36. Chen MT, Dong L, Zhang XH, Yin XL, Ning HM, Shen C et al. ZFP36L1 promotes monocyte/ macrophage differentiation by repressing CDK6. Scientific Rep 2015; 5: 16229.

37. Montero-Melendez T, Dalli J, Perretti M. Gene expression signature-based approach identifies a pro-resolving mechanism of action for histone deacetylase inhibitors. Cell Death Differ 2013; 20: 567-575.

38. Matsuo Y, MacLeod RA, Uphoff CC, Drexler HG, Nishizaki C, Katayama $Y$ et al. Two acute monocytic leukemia (AML-M5a) cell lines (MOLM-13 and MOLM-14) with interclonal phenotypic heterogeneity showing MLL-AF9 fusion resulting from an occult chromosome insertion, ins(11;9)(q23;p22p23). Leukemia 1997; 11: 1469-1477.

39. Ivey A, Hills RK, Simpson MA, Jovanovic JV, Gilkes A, Grech A et al. Assessment of minima residual disease in standard-risk AML. N Engl J Med 2016; 374: 422-433.

40. Kueh HY, Champhekar A, Nutt SL, Elowitz MB, Rothenberg EV. Positive feedback between PU.1 and the cell cycle controls myeloid differentiation. Science 2013; 341: 670-673.
41. Carter JH, Tourtellotte WG. Early growth response transcriptional regulators are dispensable for macrophage differentiation. J Immunol 2007; 178: 3038-3047.

42. Sugimoto MA, Vago JP, Teixeira MM, Sousa LP. Annexin A1 and the resolution of inflammation: modulation of neutrophil recruitment, apoptosis, and clearance. J Immunol Res 2016; 2016: 8239258.

43. Kim SH, Kim MO, Cho YY, Yao K, Kim DJ, Jeong CH et al. ERK1 phosphorylates Nanog to regulate protein stability and stem cell self-renewal. Stem Cell Res 2014; 13: 1-11.

44. Forget MA, Voorhees JL, Cole SL, Dakhlallah D, Patterson IL, Gross AC et al. Macrophage colony-stimulating factor augments Tie2-expressing monocyte differentiation, angiogenic function, and recruitment in a mouse model of breast cancer. PLOS ONE 2014; 9: e98623

45. Seipel K, Marques MT, Bozzini MA, Meinken C, Mueller BU, Pabst T. Inactivation of the p53-KLF4-CEBPA axis in acute myeloid leukemia. Clin Cancer Res 2016; 22: 746-756.

46. Saudy NS, Fawzy IM, Azmy E, Goda EF, Eneen A, Abdul Salam EM. BMl1 gene expression in myeloid leukemias and its impact on prognosis. Blood Cell Mol Dis 2014; 53: 194-198.

47. Kakiuchi S, Minami Y, Miyata Y, Mizutani Y, Goto H, Kawamoto S et al. NANOG expression as a responsive biomarker during treatment with Hedgehog signal inhibitor in acute myeloid leukemia. Int J Mol Sci 2017; 18: 486.

48. Garofalo M, Croce CM. Role of microRNAs in maintaining cancer stem cells. Adv Drug Deliv Rev 2015; 81: 53-61.

49. Yuan $\mathrm{Y}$, Kasar $\mathrm{S}$, Underbayev $\mathrm{C}$, Prakash $\mathrm{S}$, Raveche $\mathrm{E}$. MicroRNAs in acute myeloid leukemia and other blood disorders. Leuk Res Treat 2012; 2012: 603830.

50. Marcucci G, Mrozek K, Radmacher MD, Garzon R, Bloomfield CD. The prognostic and functional role of microRNAs in acute myeloid leukemia. Blood 2011; 117: 1121-1129.

51. Yendamuri S, Calin GA. The role of microRNA in human leukemia: a review. Leukemia 2009; 23: $1257-1263$.

52. Gangaraju VK, Lin H. MicroRNAs: key regulators of stem cells. Nat Rev Mol Cell Biol 2009; 10: $116-125$

53. Vargas Romero $\mathrm{P}$, Cialfi S, Palermo R, De Blasio C, Checquolo S, Bellavia D et al. The deregulated expression of miR-125b in acute myeloid leukemia is dependent on the transcription factor C/EBPalpha. Leukemia 2015; 29: 2442-2445.

54. Su R, Lin HS, Zhang XH, Yin XL, Ning HM, Liu B et al. MiR-181 family: regulators of myeloid differentiation and acute myeloid leukemia as well as potential therapeutic targets. Oncogene 2015; 34: 3226-3239.

55. Caivano A, La Rocca F, Simeon V, Girasole M, Dinarelli S, Laurenzana I et al MicroRNA-155 in serum-derived extracellular vesicles as a potential biomarker for hematologic malignancies - a short report. Cell Oncol 2016; 40: 97-103.

56. Ferrara F, Di Noto R, Viola A, Russo C, Boccuni P, Costantini S et al. Complete remission in acute myeloid leukaemia with $t(8 ; 21)$ following treatment with G-CSF: flow cytometric analysis of in vivo and in vitro effects on cell maturation. Br J Haematol 1999; 106 : 520-523.

57. De Luca L, Trino S, Laurenzana I, Simeon V, Calice G, Raimondo S et al. MiRNAs and piRNAs from bone marrow mesenchymal stem cell extracellular vesicles induce cell survival and inhibit cell differentiation of cord blood hematopoietic stem cells: a new insight in transplantation. Oncotarget 2016; 7: 6676-6692.

58. Trino S, lacobucci I, Erriquez D, Laurenzana I, De Luca L, Ferrari A et al. Targeting the p53MDM2 interaction by the small-molecule MDM2 antagonist Nutlin-3a: a new challenged target therapy in adult Philadelphia positive acute lymphoblastic leukemia patients. Oncotarget 2016; 7: 12951-12961.

59. Laurenzana I, Caivano A, Trino S, De Luca L, La Rocca F, Simeon V et al. A pyrazolo[3,4-d] pyrimidine compound inhibits Fyn phosphorylation and induces apoptosis in natural killer cell leukemia. Oncotarget 2016; 7: 65171-65184.

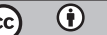

Cell Death and Disease is an open-access journal published by Nature Publishing Group. This work is licensed under a Creative Commons Attribution 4.0 International License. The images or other third party material in this article are included in the article's Creative Commons license, unless indicated otherwise in the credit line; if the material is not included under the Creative Commons license, users will need to obtain permission from the license holder to reproduce the material. To view a copy of this license, visit http://creativecommons.org/licenses/by/4.0/

(C) The Author(s) 2017 